\title{
ISU ISLAMISASI ILMU PENGETAHUAN DALAM PEMIKIRAN MUHAMMAD MUMTAZ ALI
}

\author{
Heru Saiful Anwar \\ Universitas Darussalam Gontor \\ heruanwar@unida.gontor.ac.id
}

\author{
Safiruddin Al Baqi \\ IAIN Ponorogo \\ albaqi@iainponorogo.ac.id
}

\begin{abstract}
Muslim scholars or scientists are currently faced with a dilemma of thought and actions in responding to the challenges of the globalization. On the one hand, the onslaught of western thought such as secularism and liberalism is very strong, while on the other hand they must maintain the principles of Islamic law. So that their actions do not come out of Islamic law, it is very important for Muslim scientists to understand the concept of Islamization of Science. The figure who initiated this thought was Prof. Syed Muhammad Naquib al-Attas who then continues until now, one of them is Muhammad Mumtaz Ali. Muhammad Mumtaz Ali's works related to the Islamization of Science emphasize the importance of prioritizing the Islamization of science for Muslim scientists. The spirit of Islamization must continue to be strengthened for the advancement of Muslims. The vision and mission of the Islamization of Science will be difficult to achieve if Muslims are not united to achieve it. All Muslim scientists in various fields of knowledge are expected to understand Islamic law well, so that the knowledge they spread will not conflict with the rules of Allah SWT.
\end{abstract}

Keywords: Islamization of science, Muhammad Mumtaz Ali, Islamic thought.

Abstrak: Cendekiawan atau ilmuwan muslim saat ini dihadapkan dengan dilemma pemikiran serta langkah dalam menjawab tantangan zaman. Disatu sisi, gempuran pemikiran barat seperti sekulerisme dan liberalism sangat kuat, sedankan disisi lain mereka harus tetap menjaga prinsip syariat agama Islam. Agar apa yang menjadi langkah mereka tidak keluar dari syariat Islam, maka sangat penting bagi ilmuwan muslim untuk memahami konsep Islamisasi Ilmu Pengetahuan. Tokoh yang mengawali pemikiran ini adalah Prof. Syed Muhammad Naquib alAttas yang kemudian terus berkembang hingga saat ini, salah satunya adalah Muhammad Mumtaz Ali. Karya-karya Muhammad Mumtaz Ali terkait Islamisasi Ilmu Pengetahuan menekankan bahwa pentingnya memprioritaskan islamisasi ilmu pengetahuan bagi para ilmuan muslim. Semangat Islamisasi harus terus dikuatkan demi kemajuan umat Islam. Visi dan misi Islamisasi Ilmu Pengetahuan akan sulit tercapai jika Muslim tidak bersatu untuk mencapainya. Semua ilmuwan muslim diberbagai bidang ilmu diharapkan memahami syariat Islam dengan baik, sehingga ilmu yang mereka sebarkan nantinya tidak berbenturan dengan aturan Allah SWT.

Kata kunci: Islamisasi ilmu pengetahuan, Muhammad Mumtaz Ali, pemikiran Islam. 
MA’ALIM: Jurnal Pendidikan Islam

Volume 1, Nomor 2, Desember 2020

\section{PENDAHULUAN}

Islamisasi Ilmu pengetahuan (IIP) adalah sebuah upaya tokoh-tokoh intelektual muslim untuk membebaskan umat Islam dari belenggu pemikiran sekuler dan liberal barat yang sejarahnya dibawa oleh alumni-alumni Eropa-Amerika yang silau dengan kemajuan barat - yang menurut sebagian alumninya - dengan meninggalkan ajaran agama barat maju, dan kalau umat islam menginginkan kemajuan maka tirulah barat.

Prof. Syed Muhammad Naquib al-Attas, pada Konferensi Dunia tentang Pendidikan Islam yang diadakan tanggal 30 maret - 8 April 1977, merupakan tokoh yang pertama kali mengangkat isu IIP ${ }^{1}$. Dalam merespon ide Islamisasi Ilmu Pengetahuan (IIP), beberapa pemikir muslim mencoba mengangkat isu tersebut dalam berbagai cara dan aspek. Salah satu buku yang patut menjadi bahan diskusi isu IIP adalah buku berjudul "Issues in Islamization of Human Knowledge: Civilization Building Discourse of Contemporary Muslim Thinkers”. Buku ini mengangkat isu IIP dengan menampilkan tokoh-tokoh sentral munculnya IIP dengan pengembangannya, mereka adalah ilmuan muslim kontemporer yang aktif pada gagasan IIP bahkan pelaku dilapangan, terutama dalam pendirian, maupun pengembangan isu dalam bentuk Universitas Islam, yaitu : Prof. Dr. M. Naquib al-Attas, ${ }^{2}$ Prof. Kamal Hasan, ${ }^{3}$ Dr. Abul Hamid Abu Sulaiman ${ }^{4}$, dan Prof. Ismail Raji al-Faruqi. ${ }^{5}$

\footnotetext{
${ }^{1}$ Pada Konfrensi tersebut beliau mempresentasikan sebuah makalah berjudul "Preliminary Thouths on the Nature of Knowledge and the Definition and Aims of Education”. Dalam makalah tersebut Prof. Dr. Naquib al-Attas memperkenalkan pertama kali istilah Islamisasi Ilmu Pengetahuan (IIP), dengan memperkenalkan aspek penting sebagai dasar dari IIP, seperti hakekat manusia, ilmu pengetahuan dalam prespektif Islam, definisi dan tujuan Pendidikan, sampai memunculkan ide pendirian Universitas Islam, yang dikemudian hari berdiri International Islamic University Islamabad (IIUI) di Pakistan dan Internasional Islamic University Malaysia (IIUM). Kesimpulan dari makalah tersebut adalah ilmu pengetahuan yang kehilangan tujuannya. Lihat Mohn Nor Wan Daud, Falsafah dan Amalan Pendidikan Islam Syed M. Naquib al-Attas satu Huraian Konsep Asli Islamisasi, (Kuala Lumpur: UM pres, 2014) hal 269.

2 Tan Sri Dr. Syed Muhammad al Naquib bin Ali al-Attas (Bahasa Arab: سيد محمد نقيب العطاس Sayyid Muhammad Naqib al- 'Attās: lahir 5 September 1931) adalah seorang filsuf Muslim Malaysia. Dia adalah salah satu dari sedikit sarjana kontemporer yang benar-benar berakar pada ilmu-ilmu Islam tradisional dan yang sama-sama kompeten dalam teologi, filsafat, metafisika, sejarah, dan sastra. [Rujukan?] Dia adalah pelopor dalam mengusulkan ide Islamisasi pengetahuan . Filsafat dan metodologi pendidikan Al-Attas memiliki satu tujuan: Islamisasi pikiran, tubuh dan jiwa dan dampaknya pada kehidupan pribadi dan kolektif pada umat Islam dan juga yang lain, termasuk lingkungan spiritual dan fisik non-manusia. Dia adalah penulis dua puluh tujuh karya tentang berbagai aspek pemikiran dan peradaban Islam, khususnya tentang tasawuf, kosmologi, metafisika, filsafat dan bahasa dan sastra Melayu.fism, cosmology, metaphysics, philosophy and Malay language and literature.

${ }^{3}$ Prof. Emeritus Tan Sri Dr. Mohd. Kamal bin Hassan (lahir 27 Oktober 1942 di Pasir Mas, Kelantan) adalah seorang akademisi Muslim dan sarjana Islam, yang berspesialisasi dalam pemikiran Islam kontemporer, khususnya yang berkaitan dengan wilayah Asia Tenggara. Dia adalah Rektor Universitas Islam Internasional Malaysia (IIUM) dari 1998 [1] hingga 2006
} 


\section{IDE-IDE DASAR PEMIKIR MUSLIM DALAM ISLAMISASI ILMU PENGETAHUAN}

Terdapat sembilan bab dalam buku yang ditulis oleh Muhammad Mumtaz Ali yang membahas tentang Islamisasi Ilmu Pengetahuan (IIP) dalam konteks ilmu kamanusiaan atau ilmu homaniora (Human Knowledge), kajian IIP ini adalah sebagai penguatan intelektual umat Islam, agar umat Islam lebih yakin kepada Tuhannya sebagai sumber ilmu pengetahuan ${ }^{6}$, dan sebagai titik awal umat Islam dalam kajian-kajian ilmu-ilmu apapun. Kajian IIP ini sebagai sesuatu yang universal dan manusiawi, hubungan IIP dengan pemikiran Islam serta metodologinya, dan prinsip dasar dalam ilmu pengetahuan.

Penulis memulai kajian tentang pentingnya Islamisasi Ilmu Pengetahuan ${ }^{7}$. Ide dan gagasan Islamisasi Ilmu Pengetahuan banyak disuarakan oleh kelompok pembaharu Islam. Namun ide dan gagasan awal justru dimunculkan oleh seorang ilmuwan melayu keturunan Arab, Prof. Dr. Syed Muhammad Naqib al-Attas, yang kemudian dipopulerkan oleh Ismail Raji alFaruqi ${ }^{8}$, dengan berbeda cara, meski esensinya sama. Mumtaz Ali menambahkan bahwa IIP oleh

\footnotetext{
${ }^{4}$ Profesor Emeritus Dato 'Dr. Abdul Hamid Ahmad Abu Sulaiman (lahir tahun 1936 di Mekah, Arab Saudi) adalah seorang cendekiawan, pemikir, pendidik, pendidik dan pengarang Islam terkenal di dunia internasional tentang banyak buku dan artikel tentang masalah Islam dan reformasi Islam, terutama di bidang pemikiran dan pendidikan. Saat ini ia adalah Ketua Institut Pemikiran Islam Internasional [1] (IIIT) dan merupakan Rektor Universitas Islam Internasional Malaysia (IIUM) antara tahun 1989 dan 1999.
}

5'Isma'l Rājī al-Fārūqī (Bahasa Arab: إسماعيل راجي الفاروقي Januari 1921 - 27 Mei 1986) adalah seorang filsuf Palestina-Amerika, yang secara luas diakui oleh rekan-rekannya sebagai otoritas Islam dan agama perbandingan. Dia menghabiskan beberapa tahun di Universitas Al-Azhar di Kairo, kemudian mengajar di beberapa universitas di Amerika Utara, termasuk Universitas McGill di Montreal. Dia adalah Profesor Agama di Temple University, tempat dia mendirikan dan memimpin program Studi Islam. Al-Faruqi juga merupakan pendiri International Institute of Islamic Thought. Dia menulis lebih dari 100 artikel untuk berbagai jurnal ilmiah dan majalah di samping 25 buku, yang paling terkenal adalah Etika Kristen: Sebuah Analisis Historis dan Sistematis dari Gagasan Dominannya. Dia juga mendirikan Kelompok Studi Islam dari Akademi Agama Amerika dan mengepalainya selama sepuluh tahun. Dia menjabat sebagai wakil presiden dari Kolokium Perdamaian Antaragama, Konferensi Muslim-Yahudi-Kristen dan sebagai presiden American Islamic College di Chicago.

${ }^{6}$ Tentunya lewat kitab Al-Qur'an, dan hadist-hadist Nabinya, lihat Al-Qur'an Surat Yunus 57. Disamping ayat-ayat tertentu yang membicarakan imu-ilmu tertentu, Al-Qr'an dibanyak ayat memerintahkan umat Islam untuk berfikir, menggunakan akalnya untuk tadabur tentang alam. Antara lain dalam Surat Ali Imron, 190-191, Surat Ar-Rum, 21. Al-Dzariyat, 21 dll.

${ }^{7}$ Penulis mengatakan bahwa persatuan umat Islam telah dirusak semenjak lama, dengan dipisahkannya antara pendidikan umum (sekuler) dan pendidikan tradisional (Agama), inilah yangmeyebabkan umat Islam terpecahpecah. Lihat : Muhammad Mumtaz Ali "Issues in Islamization of Human Knowledge: Civilization Building Discours of Contemporary" hal. 20.

${ }^{8}$ Dalam bukunya "Islamiczing Social Secience" lihat : Muhaimin ; "Arah Baru Pengembangan Pendidikan Islam, Pemberdayaan, Pengembangan Kulrikulum, Hingga Redifinisi Islamisasi Ilmu Pengetahuan”. (Bandung, Nuansa, 2003) hal 330. Juga lihat : Ismail Raji al-Faruqi : Tauhid; its Implication for Thought and Life (Temple University, The International Institute of Islamic Thought, 1982). 
sarjana muslim dilihat sebagai representasi keinginan semua pihak yang ingin mengenali dan mengakui kebenaran dan realitas dunia, setruktur kehidupan dan hubungan antara masyarakat terhadap kebenaran. Islamisasi Ilmu Pengetahuan bermaksud mendudukkan kembali kebenaran pada tempatnya. Dalam kitabnya mumtaz Ali tidak menyebut term dalam Islamisasi Ilmu Pengengtahuan sebagaimana yang dipakai oleh Muhammad Naquib Al-Attas, yaitu adab dan adil sebagai kata kuncinya. Karena menurut al-Attas bila adab dan keadilan tidak ditegakkan maka akan terjadi kehilangan adab (loss of Adab).

Gagasan dan ide Islamisasi sebenarnya sudah muncul semenjaknya turunnya Islam di tanah Arab, saat itu Rasulullah SAW mengislamkan pemikiran orang-orang Arab yang terjerumus terhadap paganisme ${ }^{9}$. Umat Islam ketika bersentuhan dengan dunia luar, dalam hal ini barat sekuler, maka islamisasi itu sudah menjadi keharusan, tentunya melalui term-term AlQur'an, sebagai buku induk umat Islam dengan memberikan makna-makna baru yang sesuai dengan zamannya tanpa harus keluar dari esensi Ali-Qur'an itu sendiri. Ulama-ulama besar seperti Ghozali ${ }^{10}$ umpamanya memberikan respon terhadap falasifah ${ }^{11}$. Inilah yang dimaksud dengan pengislaman.

Ketika umat Islam berhadapan dengan peradaban barat modern yang sekuler yang bebas nilai, yang mengesampingkan nila-nilai agama, datanglah seorang ulama tanah melayu Muhammad Naquib al-Attas yang mencoba meluruskan kembali Ilmu Pengetahuan yang tidak boleh bebas nilai dengan Program Islamisasi Ilmu Pengetahuan. Mengingat ilmu Pengetahuan Modern serat dengan berbagai problema karena dikonsep secara tidak adil dan telah kehilangan tujuan sebenarnya. Sehingga tujuan perdamaian dan keadilan dalam pengetahuan modern justru yang terjadi sebaliknya, justru menyebabkan kekacauan dalam kehidupan manusia itu sendiri. ${ }^{12}$

\section{PEMIKIRAN MUMTAZ ALI DALAM ISLAMISASI ILMU PENGETAHUAN}

Secara lebih mendalan, Mumtaz Ali pada membahas perlunya epistimologi dan metodologi IIP yang benar. Sesungguhnya islamisasi itu universal. Beberapa hal ditegaskan oleh Mumtaz Ali sebelum membicarakan Islamisasi Ilmu Pengetahuan bahwa Ilmu pengetahuan

\footnotetext{
${ }^{9}$ Lihat : Surat Al-Baqarah 21, Surat Al-Ikhlas, surat Alma'un dll.

${ }^{10}$ Al-Ghazali (/'ga:za:li/;14] full name Abū Hāmid Muhammad ibn Muhammad al-Ghazālī أبو حامد محمد بن محمد الغزالئ latinized Algazelus or Algazel, c. 1058 - 19 December 1111) was one of the most prominent and influential philosophers, theologians, jurists, and mystics[15][16] of Sunni Islam.[17] He was of Persian origin

${ }^{11}$ Lihat Buku karangan Imam Ghozali, Tahafutu Falasifah

12 Mumtaz Ali, Op Cit, hal 20.
} 
Modern Barat adalah produk Worldview Barat yang serat dengan nilai-nilai sekuler ${ }^{13}$, yang bertentangan dengan pandangan hidup Islam (worldview Islam). Dimana ilmu pengetahuan serat dengan nilai dan tidak netral. Sementara dalam pengetahuan barat yang berprinsip sekuler (matrialisme $^{14}$, individualism ${ }^{15}$, pragmatisme ${ }^{16}$, dan liberalisme ${ }^{17}$ ) justru menyebabkan perpecahan dikalangan umat Islam $^{18}$. Hal ini terjadi dalam rangka menjauhkan umat islam dari ajarannya yang dilakukan oleh Yahudi Internasional maupun gereja. Dan mereka sangat tahu, bila umat islam dekat dengan ajaran islam, mereka akan maju dan menguasai dunia.

Inilah yang melahirkan kesadaran baru perlunya Islamisasi Ilmu Pengetahuan dalam rangka menciptakan pemahaman baru tentang metafisika, epistimologis dan metodologis tentang pengatahuan sekuler modern ${ }^{19}$. Para filosof menggunakan metode spekulatif dan imajinatif. Karena itu dalam filsafat sepikulasi dan imajinasi diterima sebagai suatu metode pengetahuan yang valid. Selain spikulasi dan imajinasi. Menurut Mumtaz Ali, fondasi metafisika sekuler juga dibangun atas asumsi dasar moderinitas. Pandangan seperti ini yang memisahkan manusia dengan dunia supranatural dan trasendental. Artinya sekularisasi menjadi problema pemikiran

\footnotetext{
${ }^{13}$ Dalam kamus Besar Bahasa Indonesia, sekuler berarti bersif duniawi atau kebendaan (bukan bersifat keagamaan atau kerohanian).

${ }^{14}$ Materialisme adalah paham dalam filsafat yang menyatakan bahwa hal yang dapat dikatakan benar-benar ada adalah materi Pada dasarnya semua hal terdiri atas materi dan semua fenomena adalah hasil interaksi material. Materi adalah satu-satunya substansi. Sebagai teori, materialisme termasuk paham ontologi monistik. Akan tetapi, materialisme berbeda dengan teoriontologis yang didasarkan pada dualisme atau pluralisme. Dalam memberikan penjelasan tunggal tentang realitas, materialisme berseberangan dengan idealisme

${ }^{15}$ individualisme adalah sikap moral, filosofi politik, ideologi, atau pandangan sosial yang menekankan nilai moral individu. Individualis mempromosikan pelaksanaan tujuan dan keinginan seseorang sehingga menghargai independensi dan kemandirian dan menganjurkan bahwa kepentingan individu harus diutamakan daripada negara atau kelompok sosial, sambil menentang campur tangan eksternal atas kepentingan diri sendiri oleh masyarakat atau lembaga seperti pemerintah. Individualisme sering didefinisikan berbeda dengan totaliterisme, kolektivisme, dan lebih banyak bentuk sosial perusahaan.

${ }^{16}$ Pragmatisme adalah tradisi filosofis yang dimulai di Amerika Serikat sekitar tahun 1870. [1] Asal-usulnya sering dikaitkan dengan filsuf Charles Sanders Peirce, William James, dan John Dewey. Peirce kemudian menggambarkannya dalam pepatah pragmatisnya: "Pertimbangkan efek praktis dari objek konsepsi Anda. Kemudian, konsepsi Anda tentang efek tersebut adalah keseluruhan konsepsi Anda tentang objek.

${ }^{17}$ Liberalisme adalah filsafat politik dan moral yang didasarkan pada kebebasan, persetujuan dari yang diperintah, dan kesetaraan di hadapan hukum. Liberal menganut pandangan yang luas tergantung pada pemahaman mereka tentang prinsip-prinsip ini, tetapi mereka umumnya mendukung pemerintah yang terbatas, hak-hak individu (termasuk hak-hak sipil dan hak asasi manusia), kapitalisme (pasar bebas), demokrasi, sekularisme, kesetaraan gender, kesetaraan ras, internasionalisme, kebebasan berbicara, kebebasan pers dan kebebasan beragama ${ }^{18}$ pengirimanan plajar besar-besaran ke Prancis oleh Sulthan Mahmud II di Turki, justru melahirkan seorang Kamal Atartuk yang menjadikan Negara turki sekuler, dan membuat perpecahan dikalangan umat islam antara Alumni universitas Barat dan ulama tradisional.

${ }^{19}$ Dalam prespektif al-Attas, Islamisasi berbasiskan metafisika dasar Islam. Wan Suhaimi Wan Abdullah menjelaskan bahwa tasawuf merupakan filsafat ilmu yang islami. Persosalan dasar pandangan hidup islam (Islamic Worldview) yang terkait langsung dengan filsafah Ilmu terangkum dalam pembahasan konsep manusia, hakekat ilmu dan tujuan hidup manusia. Wan Suhaimi Wan Abdullah dan Mohd Zaidi Ismail, Adab dan Peradaban Karya Pengi 'tirafan untuk Syed Muhammad Naquib al-Attas, (Kuala Lumpur, MPH Publishings, 2012) hal 212.
} 
modern semenjak itu. Inilah yang menggugah para pakar muslim untuk meninjau kembali Ilmu Pengetahuan yang bebas nilai, dan membawanya kepada kesadaran baru Islamisasi Ilmu Pengetahuan.

Poin selanjutnya, Ali menjelaskan bahwa sesungguhnya ilmu pengetahuan memiliki dasar yaitu Tauhid, yaitu konsep ketuhanan yang juga meyakini kenabian dan akherat. Dasar ini lah yang ditolak oleh filsafat dan ilmuan modern barat dan diganti dengan konsep sekuler. Paham ini banyak disebarkan melalui dunia pendidikan, dan sayangnya banyak al yang kurang sesuai dengan pendangan Islam. Sehingga penting bagi ilmuwan muslim untuk menggunakan jalur pendidikan sebagai langkah awal untuk melakukan gerakan islamisasi ilmu penetahuan.

Dalam tulisan lain, Watt mengatakan bahwa ketika muslim berpikir tentang ilmu, mereka berpikir tentang apa yang disebut "ilmu untuk hidup", sedangkan ketika orang barat berpikir tentang ilmu, seringkali tentang "ilmu untuk power / kekuasaan". Dari pandangan keduanya seolah-olah ilmu dapat mengontrol objek natural dan material serta kehidupan individu dan social manusia. Namun demikian, terdapat perbedaan antara keduanya, yaitu dari sisi ilmu untuk kehidupan, terkandung nilai agama dan moral. Lebih lanjut, dalam artikelnya Bassam Tibi menyatakan bahwa Islamisasi ilmu bertujuan untuk menyaingi pandangan barat (Western view) atau "de-Westernization of knowledge". Karena pandangan barat muncul dengan dengan mengesampingkan semua hal selain pandangan yang mereka anggap ilmiah, termasuk pandangan agama (sekuler), apalagi Qur'an yang dalam Islam menjadi dasar pandangan keilmuan. Dengan misi dan tjuan ini maka islamisasi ilmu pengetahuan harusnya dilakukan disemua bidang ilmu, dengan memperhatikan metode disetiap disiplin ilmu, seperti ilmu social dan sains. Hal ini penting untuk dipahami oleh para ilmuwan muslim agar tidak terjebak pada pandangan sebelum masa Islam (Jahiliyah). ${ }^{20}$

Dalam pembahasan yang sama, Ali ditekankan pentingnya memahami Al-Qur'an karena Al-Qur'an mengandung kebenaran kebenaran, keaslian dan kebenaran yang universal (truth, authentic and universal knowledge) dan menjadi sumber dari ketiganya. Ali juga menunjukkan ayat-ayat Al-Qur'an yang menjelaskan bahwa dalam Al-Qur'an Allah juga memperkenalkan diri. Selanjutnya, Ali juga menyebutkan berbagai bukti yang menguatkan bahwa banyak penemuan ilmiah modern yang dimuat dalam Al-Qur'an serta berbagai hal yang menunjukkan bahwa ilmu

\footnotetext{
${ }^{20}$ Bassam Tibi. Culture and Knowledge: The Politics of Islamization of Knowledge as a Postmodern Project? The Fundamentalist Claim to De-Westernization. Jurnal of Theory, Culture \& Society Volume 12, tahun 1995, hal. 1-24.
} 
yang dimiliki manusia hanyalah sedikit dibandingkan ilmu Allah yang terkandung dalam AlQur'an.

Pentingnya islamisasi ilmu pengetahuan yang tidak hanya oleh pandangan Ali sendiri namun juga oleh pandangan Al-Attas. Dan dalam artikel lain, Md. Asham Ahmad ${ }^{21}$ mengatakan pentingnya pemahaman akan islamisasi ilmu terlebih dahulu sebelum bias mengimplementasikannya di berbagai bidang ilmu. Tanpa adanya pemahaman tentang konsep dan dasar-dasar dari islamisasi imu maka akan sangat sulit untuk mengaplikasikannya. Pandangan ini berfokus pada "what" yang memfokuskan pada isi atau konten, sehingga tampak bertolakbelakang dengan pandangan Langgulung yang berfokus pada "how" atau cara mengimplementasiannya. ${ }^{22}$

Pada poin selanjutnya, Ali mengungkapkan kesamaan pendapatnya dengan Mohd. Kamal Hasan untuk lebih memilih istilah Islamicisation dari pada Islamization. Hal ini didasarkan atas beberapa alasan, yaitu:

1. Istilah Islamisation biasanya memiliki arti proses konfersi menuju Islam, sedangakan Islamicisation umumnya memiliki arti proses penyesuaian terhadap prinsip-prinsip Islam. Maka Pengetahuan seharusnya disesuaikan dengan prinsip Islam melalui Wordview Islam, bukan memaksakan konversi keduanya.

2. Islamisation memiliki kata dasar Islam sedangkan Islamicisasi memiliki kata dasar Islamic. Yang dalam bahasa Indonesia lebih tepatnya adalah Islami. Seperti dalam kata Islamic Food (makanan Islami atau halal) dan Islamic Psychology (Psikologi Islami).

3. Alasan ketiga adalah bahwa makna Islamisasion mencakup padangan Islam secara teologi, ontology, aksiologi, eskatologi, dan epistimologi. Sedangkan Islamicisasi mengandung makna semua hal yang dapat diterima oleh Islam secara nilai, norma, standard dan criteria ataupun hal-hal yang sejalan dengan pandangan Islam, seperti kebaikan, integritas, kebersihan dan lain-lain yang mungkin saja dijalankan pula oleh non-muslim yang tidak bertentangan dengan nilai Islam.

\footnotetext{
${ }^{21}$ Md. Asham Ahmad merupakan anggota Centre for Shariah, Laws and Political Studies, Institute of Islamic Understanding Malaysia.

${ }^{22}$ Md. Asham Ahmad. Islamization of Knowledge: The Priority of Content Over Method. KIM: Journal of Islam and International Affairs. 2009. Hal 249-261
} 
4. Terminologi Islamisisasi terkesan inklusif ${ }^{23}$ sehingga bisa diterima oleh berbagai kalangan baik Islam sendiri ataupun Barat.

5. Islamisisation memiliki makna yang lebih luas dari Islamisasi yang mampu mencakup semua ilmu pengetahuan baik agama ataupun sains dan teknologi

6. Dengan penggunaan terminology Islamisisasi, Kamal Hassan berharap tidak ada lagi kesalahpahaman dari kata Islamisasi Ilmu Pengetahuan, yang seolah sempit, sehingga bisa diterima di kalangan muslim dan Barat.

Pada sub-bab berikutnya, Ali menyampaikan bahwa Islamisisasi Ilmu Pengetahuan harusnya di implementasikan dalam semua ilmu pengetahuan manusia. Kesalahpahaman selama ini yang terjadi adalah, bahwa islamisasi ilmu pengetahuan hanya digunakan untuk ilmu-ilmu social humaniora. Namun seharusnya bukanlah demikian, karena semua cabang ilmu membutuhkan adanya Islamisasi, sehingga tujuan dari ilmu itu sendiri dapat sejalan dengan ujuan dan pandangan Islam.

Dalam sebuah artikel, Wahbie Long ${ }^{24}$ menyatakan bahwa salah satu ilmu yang menjadi awal proyek islamisasi ilmu di IIUM adalah psikologi. Hal ini berawal dari keresahan Malik Badri sebagai ilmuwan psikologi. Badri meresahkan bahwa ilmu psikologi terlalu dipengaruhi oleh pandangan barat yang jauh berbeda dengan pandangan islam. Lebih lanjut, temuan-temuan dalam psikologi sangat berpengaruh dalam kehidupan manusia secara umum, sehingga jika terjadi kesalahan dalam sudut pandang maka akan berdampak tidak baik bagi manusia khususnya umat islam. Seperti pandangan Freud yang menyatakan emosi dasar manusia adalah seks, maka kebutuhan itu harus selalu dipenuhi, yang tentu hal ini sangat bertentangan dengan Islam.

Ali menjelaskan bahwa pada tahun 1978, Syed Muhammad Naquib Al-Attas tidak menggunakan istilah Islamization of Knowledge (Islamisasi Ilmu Pengetahuan) namun lebih memilih menggunakan istilah "Islamization of Present-day Knowledge". Istilah ini menggambarkan bahwa Islamisasi dibutuhkan dalam semua cabang ilmu modern khususnya ilmu-ilmu yang berakar dari peradaban Barat atau Yunani.

Al-Attas menakankan pentinya memahami sumber ilmu sehingga tidak terjebak dalam pandangan sekuler. Sekularisme dalam ilmu pengetahuan dianggap sangat berbahaya untuk

\footnotetext{
${ }^{23}$ Dalam kamus Besar Bahasa Indonesia, inklusif memiliki arti ketercakupan. Inklusif juga merupakan lawan kata dari eksklusif, yang berarti khusus atau keterpisahan dengan yang lain.

${ }^{24}$ Wahbie Long merupakan ilmuwan psikologi dari Fakultas Psikologi, Universitas Cape Town, Afrika Selatan
} 
ilmuan muslim karena menggiring muslim untuk membedakan antara ilmu pengetahuan dan agama sebagai sumber ilmu itu sendiri. Sebagai contoh, banyak mahasiswa muslim yang mempelajari ilmu psikologi menjadi gundah atau tidak tenang karena perbedaan antara apa yang mereka pelajari dari teori barat dengan apa yang mereka yakini dalam agama islam. Perbedaanperbedaan itu membuat mereka memilih memisahkan antara apa yang mereka pelajari dibangku kuliah dengan menjadikannya hanya sebatas ilmu pengetahuan dan saat mereka pulang, mereka menjalankan ibadah sesuai dengan yang mereka yakini tanpa menghirakan pengetahuan dibangku kuliah.

Diakhir pembahasan, Ali menyampaikan pandangan Al-Attas yang mengatakan bahwa saat ini masih banyak ilmuan muslim yang tidak menyadari bahaya dari sekulerisme dalam ilmu pengetahuan dan pendidikan. Maka dari itu perlu adanya pengakajian ulang dalam system pendidikan akademik di kalangan muslim sehingga tidak terjebak dalam pandangan sekuler.

Lebih lanjut, Ali membahas tentang kontribusi Isma'il Raji Al-Faruqi dalam Islamisasi Ilmu Pengetahuan. Pada tahun 1982, diadakan Konferensi Internasional terkait Islamisasi Ilmu Pengetahuan di Islamabad. Konferensi tersebut menghasilkan sebuah karya yang disunting oleh Al-Faruqi dengan judul Islamization of Knowledge: General Principles and Work Plan. Focus dari karya ini adalah Isamisasi dari ilmu pengetahuan modern dan pendidikan sekuler. Dalam tulisan ini dijelaskan bahwa issue islamisasi ilmu pengetahuan acap kali hilang timbul di kalangan muslim. Sehingga perlu ditekankan kepada seluruh ilmuan muslim untuk selalu membawa misi islamisasi, karena yang terpenting adalah mendahulukan kepentingan umat daripada kepentingan diri sendiri.

Menurut Al-Faruqi, dampak negative yang paling besar dari system pendidikan sekuler modern adalah terhapusnya "Visi Islam" dari kehidupan muslim yang terpelajar. Pandangan yang tertanam dalam diri mereka adalah bahwa ilmu harus relevan atau cocok untuk semua orang baik muslim maupun bukan. Mereka tergiring dengan pandangan bahwa ilmu pengetahuan modern tersebut dapat menguatkan Islam dan membuat islam lebih maju karena bisa diterima semua pihak, dengan mengesampingkan tujuan Islam sendiri.

Selanjutnya Ali menjelaskan pandangan Al-Faruqi terkait ide menggabungkan dua system pendidikan (Barat dan Islam) menjadi satu system pendidikan baru yang lebih baik. Cendekiawan muslim seharusnya tidak mengadopsi system pendidikan barat secara total sehingga mengesampingkan pandangan dan visi misi Islam. Disisi lain, umat Islam memiliki 
system pendidikan yaitu madrasah. Namun demikian, madrasah dengan system lama dirasa kurang maksimal dalam menjawab kebutuhan zaman. Sehingga Al-Faruqi beranggapan bahwa penting untuk mengambil sisi baik dari system pendidikan barat seperti kedisiplinan dan managemen organisasi dan menggabungkannya dengan visi misi madrasah dalam mengembangkan Islam dan memberikan pengetahuan islam pada Ummat. Meskipun pada praktiknya, seperti system madrasah di Indonesia masih banyak menekankan ilmu pengetahuan modern barat dari pada ilmu agama, khususnya Madrasah Negeri.

Di akhir pembahasan ini Ali menekankan pandangan Al-Faruqi tentang pentingnya islamisasi ilmu pengetahuan khususnya dalam system pendidikan agar umat ilmuan Muslim tidak terjebak dalam kepentingan pribadi, menjadikan muslim yang memiliki moral baik yang sesuai dengan tuntunan Islam.

Pada pembahasan selanjutnya, Ali menjelaskan tentang pandangan Andul Hamid Abu Sulayman. Pada edisi pertama, Al- Faruqi menjadi editor dari karya Islamization of Knowledge: General Principles and Work Plan dan pada tahun 1988, AndulHamid AbuSulayman menjadi editor pada edisi kedua. AbuSulayman merasa bahwa Islamisasi Ilmu Pengetahuan tidak hanya berfokus pada bidang akademik dan pendidikan, namun seharusnya lebih luas dari itu. Sehingga mampu memberikan solusi bagi permasalahan umat Islam saat ini secara lebih luas.

Lebih lanjut AbuSulayman menekankan bahwa pentingnya mengkaji Pemikiran dan Metodologi Islami sebagai perluasan dari focus sebelumnya yaitu pendidikan. Konsep dari AbuSulayman tersebut sebelumnya telah terjabarkan dalam disertasi Ph.D-nya pada tahun 1987 dengan judul Toward an Islamic Theory of International Relation: New Direction for Methodology and Though. Ia berpendapat bahwa sekularisme dari pendidikan yang dinyatakan oleh Al-Faruqi berupakan implikasi dari Pemikiran dan metodologi yang belum sesuai dengan visi misi Islamisasi ilmu Pengetahuan. Ketika seorang guru belum memahami konsep Islamisasi dari dasar pemikirannya, maka akan memunculkan arah berpikir dan metode serta system pendidikan yang sekuler. Dan pada kenyataannya saat ini banyak akademisi baik guru ataupun dosen yang bangga menggunakan alur berpikir barat karena dianggap lebih maju tanpa memperhatikan bahwa hal itu tidak sesuai dengan pemikiran Islam.

Senada dengan cendekiawan sebelumnya, AbuSulayman juga berpendapat bahwa Islamisasi Ilmu Pengetahuan seharusnya bisa diaplikasikan dalam semua disiplin ilmu, tidak hanya ilmu Sosial Humaniora namun juga Sain dan Teknologi. Beliu menambahkan pula bahwa 
seharusnya islamisasi ilmu pengetahuan menjadi prioritas umat Islam. Meskipun saat ini masih jauh dari harapan, karena dalam praktiknya, system pemerintahan, system pendidikan dan berbaga aspek kehidupan yang lain masih kurang sesuai dengan alur berpikir islamisasi.

Abu Sulayman menekankan bahwa intelek Muslim harus menyadari bahwa permasalahan ekoomi, social dan politik dari umat islam merupakan permasalahan yang serius dan membutuhkan perhatian khusus. Hal ini dikarenakan lemahnya pemahaman terhadap Pemikiran Islam (Islamic Though) dan metodologinya. Dampak buruknya adalah maraknya praktik korupsi, kinerja yang tidak efisien, pendidikan yang tidak memadai khususnya pendidikan islam dan merosotnya moral Umat Islam.

Ali menyampaikan hal yang menurutnya sangat penting, yaitu permasalahan motodologi dalam islamisasi ilmu pengetahuan. AbuSulayman menyatakan pemikiran Islami (Islamic though) masih dianggap gagal karena belum bisa bersaing sepenuhnya dengan pemikiran barat, sehingga tidak banyak dilirik bahkan oleh muslim sendiri. Hal ini disebabkan karena cendekiawan muslim belum menemukan metode yang tepat dalam memuskan islamisasi ilmu itu sendiri.

Ia menganggap bahwa ilmuan muslim saat ini masih kesulitan dalam mengumpulkan data dan menerapkan pendekatan motodologi yang sistematis. Mereka masih menggunakan pendekatan deduktif, sehingga masih seolah-olah hanya mencocokkan apa yang adalam realita kehidupan dengan apa yang ada di dalam Al-Qur'an dan Sunnah. AbuSulaymantidak bermaksud mendorong ilmuan muslim untuk mengikuti atau mengadopsi metode barat, namun mendorong ilmuan muslim untuk menemukan metode yang tepat sehingga hasil dari rumusan dan penelitian yang dilakukan dapat diterima secara luas.

Ali juga menekankan kembali prinsip-prinsip dari Islamisasi Ilmu Pengetahuan yang merupakan ringkasan dari tulisan Islamization of Knowledge: General Principles and Work Plan edisi 1989. Hal pertama yang harus dipahami adalah bahwa Allah SWT merupakan sumber dari semua ilmu pengetahuan. Sebagian ilmu pengetahuan telah disampaikan dalam Al-Qur'an sehingga Al-Qur'an bisa menjadi rujukan bagi ilmuan dalam mengembangkan berbagai disiplin ilmu yang mereka pelajari. Dengan dasar ini, ilmuan yang mempelajari benda terkecil seperti atom, hingga yang mempelajari antariksa dapat berpikir kembali bahwa semua yang mereka temukan atau pelajari merupakan bagian dari kekasaan dan hanya sedikit dari Ilmu yang Allah 
berikan. Maka ilmuan dari itu ilmuan muslim akan terhindar dari sifat berbangga diri, seolaholah merekalah yang menemukan dan membuat segala yang mereka pelajari.

Selanjutnya adalah dalam hal penciptaan. Disebutkan bahwa ilmuan muslim harus meyakini bahwa Allah menciptakan segala sesuatu dengan maksud tertentu, yang bisa jadi sudah manusia ketahui ataupun yang belum diketahui. Dan semua hal sudah diciptakan berdasarkan pola tertentu, seperti peredaran bintang dalam ilmu astronomi, metamorphosis hewan dalam ilmu biologi dan lain sebagainya. Disebutkan pula bahwa kebenaran dari ilmu pengetahuan yang dimiliki manusia tidak bisa melawan kebenaran yang ditetapkan oleh Allah SWT.

Mengutip Al- Faruqi yang mengemukakan 12 langkah strategi islamisasi ilmu pengetahuan untuk mencapai 5 tujuan. Lima tujuan tersebut adalah:

1. Menguasai ilmu modern

2. Menguasai ilmu (yang diwariskan) Islam

3. Mampu mengetahui relevansi Islam dalam setiap area dari ilmu modern

4. Mempu menciptakan sintesa kreatif dari hubungan keilmuan islam dan ilmu modern

5. Mampu mengembangkan Pemikiran Islam (Islamic though)

Dan untuk mencapai hal tersebut perencanaan atau strateginya adalah:

1. Menguasai ilmu modern

2. Disiplin dalam mencari tahu

3. Menguasai antologi keilmuan islam

4. Menguasai keilmuan islam

5. Membentuk relevansi yang spesifik antara Islam dan disiplin ilmu yang dipelajari

6. Memberikan penilaian kritis terhadap ilmu modern

7. Memberikan penilaian kritis terhadap keilmuan islam

8. Mencari tahu permasalahan utama dari umat (Islam)

9. Mencari tahu permasalahan manusia pada umumnya

10. Menilai secara kritis dan sisntesis

11. Menyususn kembali keilmuan berdasarkan pandangan Islam: Melalui buku bacaan universitas

12. Mendiseminasikan Islamisasi Ilmu Pengetahuan 
Sedangkan dalam edisi 1989, terdapat beberapa langkah yang dapat dilakukan dalam mencapai visi islamisasi ilmu pengetahuan, diantaranya:

1. Penciptaan pemahaman dan kesadaran (akan Islamisasi Ilmu Pengetahuan)

2. Muwujudkan Pemikiran, konsep dan metodologi Islam

3. Menguasai keilmuan islam

4. Menguasai ilmu-ilmu kontemporer (masa kini)

5. Disiplin membaca buku

6. Mengutamakan penelitian ilmiah

7. Menyiapkan kader-kader akademik

\section{PERBANDINGAN PEMIKIRAN MUMTAZ ALI}

Sebagai tambahan dan perbandingan, artikel yang ditulis oleh Rosnani Hashim dan Ssekamanya Siraje Abdallah pada tahun 2013 dengan judul Islamization of Human Knowledge in Theory and Practice: Achievements, Challenges and Prospects in the IIUM context ${ }^{25}$, dijelaskan bahwa IIUM bias menjadi contoh pergerakan islamisasi khususnya dalam dunia pendidikan. Aspek pendidikan dengan segala hal didalamnya menjadi poin penting dalam islamisasi karena bias menjadi dasar dari berbagai ilmu yang berkembang didalamnya. Selain itu terdapat beberapa hal penting yang hilang dalam pendidikan modern seperti adab dan disiplin dalam pikiran, jiwa dan raga sehingga terjadi kebingungan terkait hakekat dan tujuan ilmu itu sendiri.

Dalam menjalankan misi islamisasi IIUM merasa masih perlu adanya peningkatan yang keberlanjutan agar bias tercapai maksimal salah satunya dengan menyiapkan lulusan-lulusannya untuk menyadari pentingnya islamisasi melalui kurikulum dan lain-lain sehingga mereka mampu menyebarkan pandangan ini keseluruh dunia.

Rosnani Hashim dan Ssekamanya Siraje Abdallah menawarkan dua fase yang harus dilakukan untuk mencapai islamisasi ilmu: 1) Phase 1: the birth of the scholars, 2) Phase 2: Islamization of the knowledge.

\footnotetext{
${ }^{25}$ Rosnani Hashim \& Ssekamanya Siraje Abdallah. Islamization of Human Knowledge in Theory and Practice: Achievements, Challenges and Prospects in the IIUM context. IIUM Journal of Educational Studies Volume 1, Nomor 1 tahun 2013, hal. 1-12.
} 
MA’ALIM: Jurnal Pendidikan Islam

Volume 1, Nomor 2, Desember 2020

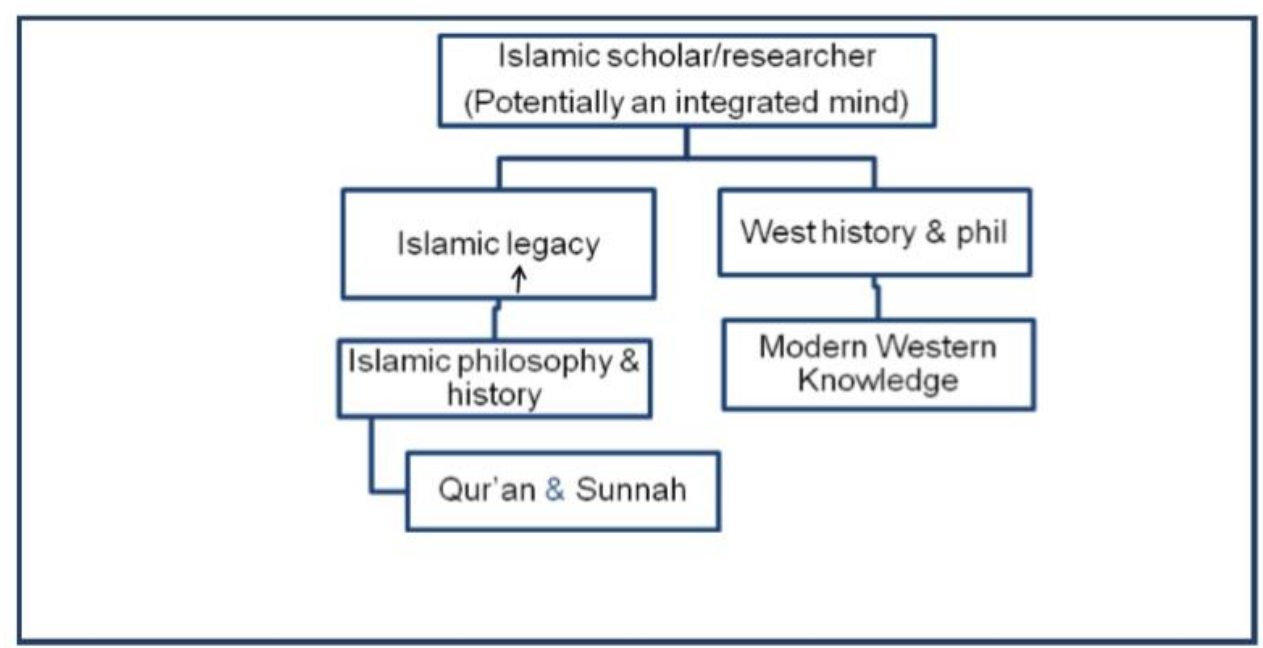

Figure 1: Phase 1-Birth of the scholar

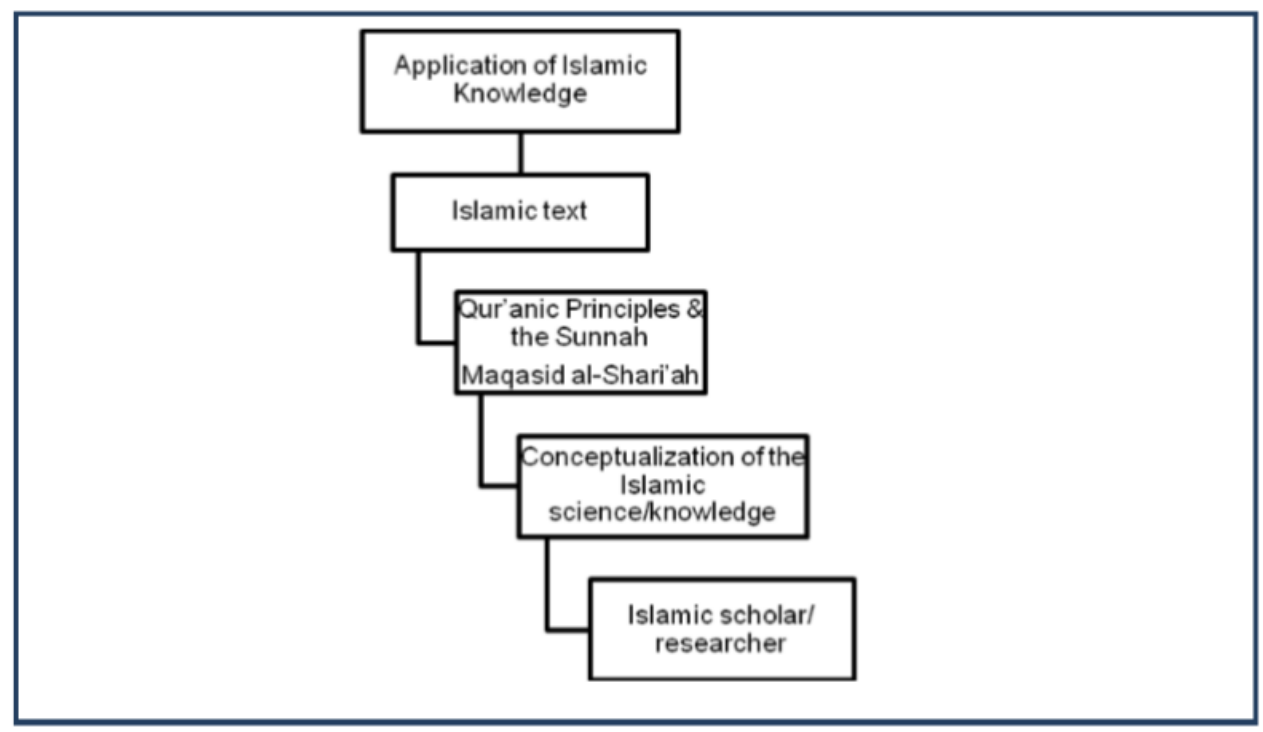

Figure 2: Phase 2 - Islamized knowledge \& products

Namun demikian, terdapat beberapa kendala dalam implementasi Islamisasi ilmu pengetahuan dalam dunia pendidikan. Seperti yang disampaikan oleh Adebayo dan Rafiu Ibrahim $^{26}$ yang menyatakan bahwa Islamisasi ilmu bukan tanpa tantangan dan kendala maka perlu dipikirkan terkait solusi dari masing-masing hambatan yang ada.

Penelitian mereka di Universitas Islam Nigeria menunjukkan beberapa hambatan yang ditemui, diantaranya:

\footnotetext{
${ }^{26}$ Penulis merupakan Doktor dan Associate Professor Fakultas Agam, Universitas Ilorin, Ilorin, Nigeria
} 
1. Tidak adanya model islamisasi yang diterima secara universal;

2. Kekurangan staf yang mampu melakukan islamisasi;

3. Masalah dengan pendanaan program Islamisasi; banyak siswa yang tidak tertarik dengan islamisasi; dan

4. Tantangan terkait dengan bahasa pengantar yaitu bahasa Arab. ${ }^{27}$

\section{KESIMPULAN}

Islamisasi Ilmu pengetahuan merupakan hal yang sangat penting untuk dicapai, yang bertujuan untuk membebaskan umat Islam dari belenggu pemikiran sekuler dan liberal barat yang sejarahnya dibawa oleh alumni-alumni Eropa-Amerika yang silau dengan kemajuan barat yang menurut sebagian alumninya - dengan meninggalkan ajaran agama barat maju, dan kalau umat islam menginginkan kemajuan maka tirulah barat. Tokoh yang mengawali Islamisasi ilmu pengetahuan salah satunya adalah Prof. Syed Muhammad Naquib al-Attas dan kemudian dilanjutkan oleh tokolh lain seperti Muhammad Ali. Dalam pemikirannya, Ali menekankan kembali pentingnya memprioritaskan islamisasi ilmu pengetahuan bagi para ilmuan muslim. Semangat Islamisasi harus terus dikuatkan demi kemajuan umat Islam. Visi dan misi Islamisasi Ilmu Pengetahuan akan sulit tercapai jika Muslim tidak bersatu untuk mencapainya.

\section{DAFTAR PUSTAKA}

Daud, Mohn Nor Wan. (2014). Falsafah dan Amalan Pendidikan Islam Syed M. Naquib al-Attas satu Huraian Konsep Asli Islamisasi. Kuala Lumpur: UM Press.

Muhaimin. (2003). Arah Baru Pengembangan Pendidikan Islam, Pemberdayaan, Pengembangan Kulrikulum, Hingga Redifinisi Islamisasi Ilmu Pengetahuan. Bandung: Nuansa.

al-Faruqi, Ismail Raji. (1982). Tauhid; its Implication for Thought and Life. Temple University: The International Institute of Islamic Thought.

Ali, Muhammad Mumtaz. (2014). Issues in Islamization of Human Knowledge: Civilization Building Discours of Contemporary Muslim Thinker". Kuala Lumpur. IIUM Press.

\footnotetext{
${ }^{27}$ Rafiu Ibrahim Adebayo. The Challenges of Islamization of Knowledge in Nigerian Islamic Universities. IIUM Journal Of Educational Studies, Volume 4, Nomor 1, tahun 2016, hal. 78 - 99
} 
Abdullah, Wan Suhaimi Wan \& Ismail, Mohd Zaidi. (2012). Adab dan Peradaban Karya Pengi'tirafan untuk Syed Muhammad Naquib al-Attas. Kuala Lumpur: MPH Publishings.

Tibi, Bassam Tibi. (1995). Culture and Knowledge: The Politics of Islamization of Knowledge as a Postmodern Project? The Fundamentalist Claim to De-Westernization. Jurnal of Theory, Culture \& Society, Volume 12, hal. 1-24.

Ahmad, Md. Asham. (2009). Islamization of Knowledge: The Priority of Content Over Method. KIM: Journal of Islam and International Affairs. hal 249-261.

Hashim, Rosnani Hashim \& Abdallah. (2013). Sekamanya Siraje Abdallah. Islamization of Human Knowledge in Theory and Practice: Achievements, Challenges and Prospects in the IIUM context. IIUM Journal of Educational Studies Volume 1, Nomor, hal. 1-12.

Adebayo, Rafiu Ibrahim. (2016). The Challenges of Islamization of Knowledge in Nigerian Islamic Universities. IIUM Journal Of Educational Studies, Volume 4, Nomor 1, hal. 78 99. 